\title{
Estimates of Genetic Parameters for Canadian Holstein Female Reproduction Traits
}

\author{
J. Jamrozik, ${ }^{1}$ J. Fatehi, ${ }^{1}$ G. J. Kistemaker, ${ }^{2}$ and L. R. Schaeffer ${ }^{1}$ \\ ${ }^{1}$ Centre for Genetic Improvement of Livestock, Department of Animal and Poultry Science, \\ University of Guelph, ON, Canada N1G 2W1 \\ ${ }^{2}$ Canadian Dairy Network, Guelph, ON, Canada N1G 4T2
}

\section{ABSTRACT}

Age at first insemination, days from calving to first insemination, number of services, first-service nonreturn rate to $56 \mathrm{~d}$, days from first service to conception, calving ease, stillbirth, gestation length, and calf size of Canadian Holstein cows were jointly analyzed in a linear multiple-trait model. Traits covered a wide spectrum of aspects related to reproductive performance of dairy cows. Other frequently used fertility characteristics, like days open or calving intervals, could easily be derived from the analyzed traits. Data included 94,250 records in parities 1 to 6 on 53,158 cows from Ontario and Quebec, born in the years 1997 to 2002 . Reproductive characteristics of heifers and cows were treated as different but genetically correlated traits that gave 16 total traits in the analysis. Repeated records for later parities were modeled with permanent environmental effects. Direct and maternal genetic effects were included in linear models for traits related to calving performance. Bayesian methods with Gibbs sampling were used to estimate covariance components of the model and respective genetic parameters. Estimates of heritabilities for fertility traits were low, from $3 \%$ for nonreturn rate in heifers to $13 \%$ for age at first service. Interval traits had higher heritabilities than binary or categorical traits. Service sire, sire of calf, and artificial insemination technician were important (relative to additive genetic) sources of variation for nonreturn rate and traits related to calving performance. Fertility traits in heifers and older cows were not the same genetically (genetic correlations in general were smaller than 0.9). Genetic correlations (both direct and maternal) among traits indicated that different traits measured different aspects of reproductive performance of a dairy cow. These traits could be used jointly in a fertility index to allow for selection for better fertility of dairy cattle.

(Key words: dairy cow, fertility trait, genetic parameter)

Received November 24, 2004.

Accepted February 28, 2005.

Corresponding author: J. Jamrozik; e-mail: jjamrozi@uoguelph.ca.
Abbreviation key: AFS = age at first service, $\mathbf{C E}=$ calving ease, CTFS = interval from calving to first service, $\mathbf{C Z}=$ calf size, $\mathbf{F S T C}=$ interval from first service to conception, $\mathbf{G L}=$ gestation length, $\mathbf{N R R}=$ nonreturn rate to $56 \mathrm{~d}, \mathbf{N S}=$ number of services, $\mathbf{S B}=$ stillbirth.

\section{INTRODUCTION}

Selection for higher yields of dairy cattle has led to a decline in fertility due to unfavorable genetic correlations between yield and fertility (Pryce et al., 2004). Work by Westell et al. (1992) on Canadian data showed that $25 \%$ of cow disposal reasons were attributed to reproductive failure. This figure might have changed in recent years, but nevertheless, decreased fertility is a problem in the Canadian dairy industry. Canada has only recently implemented a national recording scheme for fertility traits as part of the new milk recording system. Insemination data have been accumulated since 1997 and the national genetic evaluation program for fertility traits of cows can now be developed. Preliminary results from the genetic evaluation model for 4 fertility traits (age at first service in heifers, nonreturn rate to $56 \mathrm{~d}$ in heifers and cows, and the interval from calving to first insemination) for Canadian dairy breeds were reported recently by Van Doormaal et al. (2004).

Reproductive events occur during the lifetime of a dairy cow. There is the first estrus that occurs at a particular age. This is followed by the first insemination, the second insemination, and so on until conception occurs. Most cows will have a normal gestation length of around $280 \mathrm{~d}$. Calving difficulty and stillbirth can be recorded at calving. The cow begins milk production after calving and the level of production could affect subsequent fertility. This cycle is repeated after each calving.

Determining which traits to include in genetic evaluation for fertility is difficult. Many earlier studies on cow reproduction had only calving dates from which calving intervals or days open could be computed, assuming a standard gestation length (Jansen, 1986). This assumption has not always been correct because of possible differences in gestation length between different service sires. The availability of insemination data has allowed 
the calculation of intervals between calving and each insemination as well as the number of inseminations. Age at first insemination, age at conception, and the intervals from calving to first service and first service to conception in each lactation have been important traits in several studies. Nonreturn rates of service sires have been evaluated in Canada for several years (Schaeffer, 1993), but these evaluations have been phenotypic rather than genetic, and on sires, not cows. Dilution of semen before freezing, age of the sire when collected, and AI technician all have large effects on fertility. Therefore the measurable heritability is lower than the true heritability. The fertility of a service sire can change over time because of the manner in which the semen was processed. Calving difficulty and stillbirth (or calf mortality) may influence subsequent rebreeding success of a cow in a given lactation. Both of these traits are controlled by the genetic effect of the cow and genetic effect of the sire of the calf, so both effects must be considered in a model. Gestation length and size of calf are factors (among others) that have an effect on dystocia and stillbirth.

Reproductive performance of a cow is therefore an array of several traits. They are observed around each pregnancy so that a cow may have repeated measurements as she ages. Fertility can change with age of the cow, often depending on previous performance (Jansen et al., 1987). The literature indicates that heifer fertility traits had higher heritabilities than cow traits (Jansen, 1986; Muir et al., 2004), and the inclusion of heifer fertility traits in the analysis seems vital because they can be measured early, even though the relationship to later fertility measures may be weak. The heritabilities of most reproductive traits were generally below 0.10 (Kadarmideen et al., 2003; Wall et al., 2003). Even though heritabilities were quite small, the additive genetic variation for these traits was deemed sufficient to allow effective selection for fertility (Weller and Ron, 1992; Boichard and Manfredi, 1994; Weigel and Rekaya, 2000). By considering a wide spectrum of fertility traits simultaneously in a multiple trait model, a better evaluation of reproductive ability might be achieved with an increase in accuracy of estimated breeding values for individual traits.

Environmental factors were found to have a very large effect on fertility traits (Hayes et al., 1992). Herd management, year, month during the year, age at calving, and age at insemination (within parity) were all factors that affected fertility in different studies (Thaller, 1997).

Objectives of this study were to estimate covariance components and corresponding genetic parameters for a selected set of 16 female fertility traits for the Canadian Holstein population, and to examine genetic and envi- ronmental relationships between different reproductive traits in heifers and older cows.

\section{MATERIALS AND METHODS}

\section{Data}

Data on Holstein reproductive traits were obtained from Canadian Dairy Network. These were insemination records collected by AI organizations and milk recording agencies that were matched to pedigree, lactation, and calving performance information to be able to calculate the traits of interest. Fertility traits were defined based on data availability in a way that would describe a complete picture of a reproductive history for a cow. The traits selected for this study were as follows: age at first insemination (AFS), days from calving to first insemination (CTFS), number of services (NS), first-service nonreturn rate to $56 \mathrm{~d}$ (NRR), days from first service to conception (FSTC), calving ease (CE), stillbirth (SB), gestation length $(\mathbf{G L})$, and calf size $(\mathbf{C Z})$. First-service NRR was used only as an early indication of conception rate. Conception date was determined using subsequent calving date that agreed with the latest insemination data. Continuous, interval traits (AFS, CTFS, FSTC, and GL) were expressed in days. Gestation length was measured as an interval from the last insemination to the subsequent calving. Stillbirth was defined as 0 (dead) or 1 (alive calf). Nonreturn rate was coded 1 when there was no subsequent insemination between 15 and $56 \mathrm{~d}$ following the first service, and 0 otherwise. A subsequent service within $15 \mathrm{~d}$ of insemination was discarded and it was treated as a part of the same fertility event. Ordered, categorical traits (CE and $\mathrm{CZ}$ ) were subjectively scored in 4 classes (CE from 1 to 4 and $\mathrm{CZ}$ from 0 to 3 ) with 1 corresponding to unassisted calving $(\mathrm{CE})$ and 0 describing small calf size (CZ). One trait, AFS, was considered a heifer trait only. Similarly, CTFS was defined for cows only. All remaining traits were defined for both heifer and older cows. All traits recorded during or before the first calving were considered heifer traits, and they were coded as parity 1 . Traits measured on first-lactation animals were coded as parity 2 , and the same scheme was applied to remaining $(>2)$ lactations.

Time edits were applied to eliminate censored records for animals that were born or calved recently. In addition, animals that had part of their fertility events before the start of data collection were also removed. This was to ensure that all cows in the data had a virgin heifer record. Therefore, only records on cows that were born in years 1997 to 2002 could be used. First insemination of heifers occurred in years 1998 to 2004, calving years were 1999 to 2004 . All cows had to have sire identified. Other requirements included: age at first calving had to be greater than 18 mo, AFS between 274 and $639 \mathrm{~d}$, 
Table 1. Descriptive statistics of the data used.

\begin{tabular}{|c|c|c|c|c|c|c|}
\hline Parity & Trait $^{1}$ & $\begin{array}{l}\text { No. of } \\
\text { records }\end{array}$ & Mean & $\mathrm{SD}$ & Minimum & Maximum \\
\hline \multirow[t]{8}{*}{ First } & AFS & 53,158 & 499.7 & 53.6 & 275 & 639 \\
\hline & NRR & 53,158 & 0.74 & 0.44 & 0 & 1 \\
\hline & NS & 53,093 & 1.64 & 1.09 & 1 & 10 \\
\hline & FSTC & 29,907 & 16.3 & 31.4 & 0 & 206 \\
\hline & GL & 29,907 & 279.6 & 6.1 & 240 & 300 \\
\hline & $\mathrm{CE}$ & 29,907 & 1.63 & 0.71 & 1 & 4 \\
\hline & SB & 27,643 & 0.90 & 0.30 & 0 & 1 \\
\hline & $\mathrm{CZ}$ & 27,418 & 2.03 & 0.60 & 0 & 3 \\
\hline \multirow[t]{8}{*}{ Later } & NRR & 41,092 & 0.57 & 0.49 & 0 & 1 \\
\hline & NS & 37,409 & 2.14 & 1.50 & 1 & 10 \\
\hline & CTFS & 35,474 & 87.1 & 29.4 & 16 & 244 \\
\hline & FSTC & 16,124 & 32.5 & 44.4 & 0 & 206 \\
\hline & GL & 16,124 & 280.5 & 6.3 & 240 & 300 \\
\hline & $\mathrm{CE}$ & 16,124 & 1.41 & 0.59 & 1 & 4 \\
\hline & SB & 15,416 & 0.96 & 0.19 & 0 & 1 \\
\hline & $\mathrm{CZ}$ & 15,371 & 2.16 & 0.64 & 0 & 3 \\
\hline
\end{tabular}

\footnotetext{
${ }^{1}$ Traits ordered in their sequence of occurrence; $\mathrm{AFS}=$ age at first service, $\mathrm{CE}=$ calving ease, $\mathrm{CTFS}=$ interval from calving to first service, $\mathrm{CZ}=$ calf size, $\mathrm{FSTC}=$ interval from first service to conception, $\mathrm{GL}=$ gestation length, NRR = nonreturn rate to $56 \mathrm{~d}$, NS = number of services, $\mathrm{SB}=$ stillbirth.
}

CTFS between 14 and $244 \mathrm{~d}$. Number of services was assigned to 10 when the actual NS was greater than 10.

For estimating genetic parameters, further restrictions were needed. A subset of the data (approximately $10 \%$ of the total records after edits) was generated by a random sampling of herds with at least 20 records from Ontario and Quebec and with no restrictions on conception rates for bulls and herds. Descriptive statistics for each trait are shown in Table 1 . All cows were required to have a heifer record. Records for each calving were included only if a cow had records on all preceding calvings. Sequential edits on missing traits within parity (traits ordered in their sequence of occurrence as in Table 1) were used to account for selection biases and to facilitate computations. Total number of cows with data was 53,158 and the total number of records (each calving treated as separate record) was 94,250. Distribution of records by parity is given in Table 2 . Fertility records up to sixth calving were present in the selected data. Heifer records, however, constituted $56.4 \%$ of the total data. Total number of animals in pedigrees was 195,713. Number of service sire by year of insemination classes and number of records for sires of calf pedigrees were 3466 and 6032 , respectively.

Table 2. Distribution of records by parity number.

\begin{tabular}{lc}
\hline Parity & No. of records \\
\hline 1 & 53,158 \\
2 & 24,989 \\
3 & 10,927 \\
4 & 4046 \\
5 & 1010 \\
6 & 120 \\
\hline
\end{tabular}

\section{Models}

All models (genetic and environmental factors, in particular) were developed based on our knowledge of genetics of reproduction, data availability, literature evidence, genetic evaluation models for fertility traits that are used in other countries, and available computing resources. Linear animal models were used although some of the analyzed traits were binary (NRR, SB) or categorical (CE, CZ).

Specific single-trait models for particular traits are listed below in a simplified scalar notation. Models for heifer traits were:

$$
\begin{aligned}
& \mathrm{AFS}=\mathrm{RYS}+\mathrm{H}(\mathrm{RYS})+\mathrm{A}+\mathrm{E} \\
& \mathrm{NRR}=\mathrm{RYS}+\mathrm{H}(\mathrm{RYS})+\mathrm{Mf}+\mathrm{SS}+\mathrm{T}+\mathrm{A}+\mathrm{E} \\
& \mathrm{NS}=\mathrm{RYS}+\mathrm{H}(\mathrm{RYS})+\mathrm{Mf}+\mathrm{A}+\mathrm{E} \\
& \mathrm{FSTC}=\mathrm{RYS}+\mathrm{H}(\mathrm{RYS})+\mathrm{Mf}+\mathrm{A}+\mathrm{E} \\
& \mathrm{GL}=\mathrm{RYS}+\mathrm{H}(\mathrm{RYS})+\mathrm{MfX}+\mathrm{SC}+\mathrm{A}+\mathrm{E} \\
& \mathrm{CE}=\mathrm{RYS}+\mathrm{H}(\mathrm{RYS})+\mathrm{AcMcX}+\mathrm{SC}+\mathrm{A}+\mathrm{E} \\
& \mathrm{SB}=\mathrm{RYS}+\mathrm{H}(\mathrm{RYS})+\mathrm{AcMcX}+\mathrm{SC}+\mathrm{A}+\mathrm{E} \\
& \mathrm{CZ}=\mathrm{RYS}+\mathrm{H}(\mathrm{RYS})+\mathrm{AcMcX}+\mathrm{SC}+\mathrm{A}+\mathrm{E}
\end{aligned}
$$

Similarly, for cow traits:

$$
\begin{aligned}
& \mathrm{NRR}=\mathrm{RYS}+\mathrm{H}(\mathrm{RYS})+\mathrm{ApMf}+\mathrm{SS}+\mathrm{T}+\mathrm{A}+\mathrm{PE}+\mathrm{E}, \\
& \mathrm{NS}=\mathrm{RYS}+\mathrm{H}(\mathrm{RYS})+\mathrm{ApMf}+\mathrm{A}+\mathrm{PE}+\mathrm{E}, \\
& \mathrm{CTFS}=\mathrm{RYS}+\mathrm{H}(\mathrm{RYS})+\mathrm{ApMp}+\mathrm{A}+\mathrm{PE}+\mathrm{E},
\end{aligned}
$$




$$
\begin{aligned}
& \mathrm{FSTC}=\mathrm{RYS}+\mathrm{H}(\mathrm{RYS})+\mathrm{ApMf}+\mathrm{A}+\mathrm{PE}+\mathrm{E}, \\
& \mathrm{GL}=\mathrm{RYS}+\mathrm{H}(\mathrm{RYS})+\mathrm{ApMpX}+\mathrm{SC}+\mathrm{A}+\mathrm{PE}+\mathrm{E}, \\
& \mathrm{CE}=\mathrm{RYS}+\mathrm{H}(\mathrm{RYS})+\mathrm{AcMcX}+\mathrm{SC}+\mathrm{A}+\mathrm{PE}+\mathrm{E}, \\
& \mathrm{SB}=\mathrm{RYS}+\mathrm{H}(\mathrm{RYS})+\mathrm{AcMcX}+\mathrm{SC}+\mathrm{A}+\mathrm{PE}+\mathrm{E}, \\
& \mathrm{CZ}=\mathrm{RYS}+\mathrm{H}(\mathrm{RYS})+\mathrm{AcMcX}+\mathrm{SC}+\mathrm{A}+\mathrm{PE}+\mathrm{E},
\end{aligned}
$$

where RYS was a fixed effect of region by year of birth by season of birth; H(RYS) was a random effect of herd within RYS; Mf was a fixed effect of month of first insemination; MfX was a fixed effect of month of first insemination by sex of calf; AcMcX was a fixed effect of age at current calving by month of current calving, by sex of calf by parity; ApMp was a fixed effect of age at previous calving by month of previous calving by parity; ApMf was a fixed effect of age at previous calving by month of first insemination by parity; ApMpX was a fixed effect of age at previous calving by month of previous calving by sex of calf by parity; A was a random animal additive genetic effect; SS was a random effect of service sire by year of insemination; SC was a random effect of sire of calf, $\mathrm{PE}$ was a random permanent environmental effect; $\mathrm{T}$ was a random effect of $\mathrm{AI}$ technician; and $\mathrm{E}$ was a random error term. Year of insemination in the SS effect was included to account (at least partially) for the season of semen collection and the age of service sire, factors that might influence insemination results.

Age classes were set up on a monthly scale. Only one age category (current or previous parity number) was assigned to records with parity number greater than 2 . This was done due to small number of observations in ApMp, ApMf, ApMpX, and AcMc classes for parities 3, 4,5 , and 6. Four seasons of birth were defined as: December-February, March-June, July-September, and October-November. Sex of calf was coded in 3 categories: female, male, and unknown (unrecorded) sex.

The overall model was a multiple-trait model that included all 16 traits with specific linear models for particular traits as shown above. Residuals for all heifer traits were allowed to be correlated, and similarly residual correlations between all later parity traits (within a given parity) could have been different from zero. All residual covariances between 2 traits from different parities were equal to zero. Random SS, SC, T, A, and PE effects were uncorrelated between each other. This meant in particular, that all correlations between additive genetic effects and sire of calf effects were equal to zero. Correlations were allowed, however, between SS (SC, T) effects for different traits and parities. Animal genetic effects (A) allowed for full correlation structure (nonzero correlations between traits and parities). Covariances between levels of SC were realized through bull-sire-maternal grandsire relationships. Effects of PE were also correlated among all cow traits.

In matrix notation, the model can be written as

$$
\mathbf{y}=\mathbf{X} \mathbf{b}+\mathbf{Z}_{1} \mathbf{r}+Z_{2} \mathbf{a}+Z_{3} \mathbf{p}+Z_{4} \mathbf{c}+Z_{5} \mathbf{s}+Z_{6} \mathbf{t}+\mathbf{e}
$$

where $\mathbf{y}$ is a vector of observations (traits within parities within cows), $\mathbf{b}$ is a vector of all fixed effects, $\mathbf{r}$ is a vector of $\mathrm{H}(\mathrm{RYS})$ effects, $\mathbf{a}$ is a vector of animal additive genetic effects (A), $\mathbf{p}$ is a vector of $\mathrm{PE}$ effects, $\mathbf{c}$ is a vector of sire of calf (SC) effects, $\mathbf{s}$ is a vector of service sire (SS) effects, $\mathbf{t}$ is a vector of AI technician (T) effects, $\mathbf{e}$ is a vector of residuals, and $\mathbf{X}$ and $\mathbf{Z}_{\mathbf{i}}(\mathrm{i}=1,6)$ are respective incidence matrices. Assumptions were that

$$
\left[\mathbf{r}^{\prime} \mathbf{a}^{\prime} \mathbf{p}^{\prime} \mathbf{c}^{\prime} \mathbf{s}^{\prime} \mathbf{t}^{\prime} \mathbf{e}^{\prime}\right]^{\prime} \sim \mathrm{N}[\mathbf{0}, \mathbf{V}] \text { with } \mathbf{V}=\sum_{i=1}^{7} \mathbf{V}_{\mathbf{i}}
$$

where $\mathbf{V}_{1}=\mathbf{I} \otimes \mathbf{R}, \mathbf{I}$ is an identity matrix, $\mathbf{R}$ is a covariance $(16 \times 16)$ matrix for $\mathrm{H}(\mathrm{RYS})$ effects; $\mathbf{V}_{2}=\mathbf{A} \otimes \mathbf{G}$, $\mathbf{A}$ is an additive relationship matrix, $\mathbf{G}$ is a genetic covariance $(16 \times 16)$ matrix; $\mathbf{V}_{3}=\mathbf{I} \otimes \mathbf{P}, \mathbf{P}$ is a covariance $(8$ $\times 8)$ matrix for PE effect; $\mathbf{V}_{4}=\mathbf{A}_{\mathbf{s}} \otimes \mathbf{C}, \mathbf{A}_{\mathbf{s}}$ is a sirematernal grandsire relationship matrix, $\mathbf{C}$ is a covariance $(8 \times 8)$ matrix for SC effect; $\mathbf{V}_{5}=\mathbf{I} \otimes \mathbf{S}, \mathbf{S}$ is a covariance $(2 \times 2)$ matrix for SS effect; $\mathbf{V}_{6}=\mathbf{I} \otimes \mathbf{T}$, $\mathbf{T}$ is a covariance $(2 \times 2)$ matrix for $\mathrm{T}$ effect; $\mathbf{V}_{7}=\sum_{i=1}^{N}{ }^{+} \mathbf{E}_{\mathbf{i}}, \mathbf{E}_{\mathbf{i}}$ is a residual covariance matrix (of order up to $8 \times 8$, depending on how many traits were missing) for either first or later calvings, $\mathrm{N}$ is the total number of records, $\Sigma^{+}$and $\otimes$ are Kronecker sum and product operators (Searle, 1982), respectively.

The genetic model for a trait influenced by both the cow effect and the effect of the sire of calf (GL, CE, SB and CZ) can be described following Wilham (1963) as

$$
\mathrm{w}_{\mathrm{ij}}=\mathrm{a}_{\mathrm{i}}+\mathrm{c}_{\mathrm{j}}+\mathrm{e}_{\mathrm{ij}},
$$

where $w_{i j}$ is the value of trait, $a_{i}$ is the cow effect, $c_{j}$ is the sire of calf effect, and $e_{i j}$ is the error term. Additive genetic and sire of calf effect can then be expressed as:

$$
\begin{gathered}
\mathrm{a}_{\mathrm{i}}=0.5 \mathrm{~d}_{\mathrm{i}}+\mathrm{m}_{\mathrm{i}} \text {, and } \\
\mathrm{c}_{\mathrm{j}}=0.5 \mathrm{~d}_{\mathrm{j}},
\end{gathered}
$$

where $d_{i}$ is the direct genetic effect and $m_{i}$ is maternal genetic effect. Direct $\left(\mathbf{G}_{\mathrm{d}}\right)$ and maternal $\left(\mathbf{G}_{\mathrm{m}}\right)$ covariance matrices can be derived from additive genetic and sire of calf covariances as:

$$
\begin{array}{r}
\mathbf{G}_{\mathrm{d}}=4 \mathbf{C} \text { and } \\
\mathbf{G}_{\mathrm{m}}=\mathbf{G}-\mathbf{C},
\end{array}
$$


Table 3. Estimates (posterior means) of phenotypic variance and ratios with respect to phenotypic variance for maternal genetic $\left(\mathrm{m}^{2}\right)$, herd within region-year-season $\left[\mathrm{h}(\mathrm{rys})^{2}\right]$, permanent environment $\left(\mathrm{pe}^{2}\right)$, direct genetic $\left(\mathrm{d}^{2}\right)$, service sire $\left(\mathrm{ss}^{2}\right)$, technician $\left(\right.$ tech $\left.{ }^{2}\right)$, and residual $\left(\mathrm{e}^{2}\right)$ variances (posterior standard deviations in parentheses).

\begin{tabular}{|c|c|c|c|c|c|c|c|c|c|}
\hline Parity & Trait $^{1}$ & $\begin{array}{l}\text { Total } \\
\text { variance }\end{array}$ & $\begin{array}{l}\mathrm{m}^{2} \\
(\%)\end{array}$ & $\begin{array}{l}\mathrm{h}(\mathrm{rys})^{2} \\
(\%)\end{array}$ & $\begin{array}{l}\mathrm{pe}^{2} \\
(\%)\end{array}$ & $\begin{array}{l}\mathrm{d}^{2} \\
(\%)\end{array}$ & $\begin{array}{l}\mathrm{ss}^{2} \\
(\%)\end{array}$ & $\begin{array}{l}\text { tech }^{2} \\
(\%)\end{array}$ & $\begin{array}{l}\mathrm{e}^{2} \\
(\%)\end{array}$ \\
\hline \multirow{5}{*}{ First } & AFS & $2845.8(23.8)$ & $13.4(1.3)$ & $48.0(0.5)$ & & & \multirow{5}{*}{$0.1(0.02)$} & \multirow{5}{*}{$0.4(0.1)$} & $38.6(1.1)$ \\
\hline & NRR & $0.19(0.001)$ & $2.9(0.6)$ & $2.0(0.2)$ & & & & & $95.1(0.6)$ \\
\hline & FSTC & $1458.6(11.7)$ & $3.0(0.6)$ & $3.7(0.3)$ & & & & & $93.2(0.7)$ \\
\hline & GL & $39.2(0.44)$ & $12.9(1.6)$ & $1.5(0.2)$ & & $30.7(3.0)$ & & & $70.3(1.4)$ \\
\hline & $\mathrm{CE}$ & $0.49(0.005)$ & $13.8(1.8)$ & $14.7(0.6)$ & & $7.8(1.4)$ & & & $67.6(1.7)$ \\
\hline \multirow[t]{7}{*}{ Later } & NRR & $0.24(0.002)$ & $4.0(0.6)$ & $2.6(0.2)$ & $0.4(0.1)$ & & \multirow[t]{7}{*}{$0.2(0.05)$} & \multirow[t]{7}{*}{$0.5(0.1)$} & $92.3(0.6)$ \\
\hline & NS & $2.24(0.02)$ & $6.9(1.0)$ & $2.7(0.2)$ & $0.1(0.03)$ & & & & $90.3(1.0)$ \\
\hline & CTFS & $862.8(7.6)$ & $9.9(1.0)$ & $20.7(0.7)$ & $1.6(0.6)$ & & & & $67.8(0.9)$ \\
\hline & FSTC & $2937.4(29.6)$ & $7.0(0.9)$ & $3.3(0.4)$ & $0.2(0.05)$ & & & & $89.5(0.9)$ \\
\hline & GL & $39.9(0.54)$ & $9.1(1.5)$ & $1.6(0.2)$ & $2.0(0.6)$ & $26.8(3.4)$ & & & 73.9 (1.3) \\
\hline & $\mathrm{CE}$ & $0.33(0.004)$ & $6.3(1.0)$ & $15.4(0.8)$ & $0.4(0.2)$ & $7.5(1.6)$ & & & $74.1(1.1)$ \\
\hline & SB & $0.03(0.0004)$ & $1.7(0.6)$ & $0.6(0.1)$ & $1.3(0.4)$ & $1.2(0.4)$ & & & $95.8(0.7)$ \\
\hline
\end{tabular}

\footnotetext{
${ }^{1}$ Traits ordered in their sequence of occurrence; AFS = age at first service, $\mathrm{CE}=$ calving ease, $\mathrm{CTFS}=$ interval from calving to first service, $\mathrm{CZ}=$ calf size, FSTC = interval from first service to conception, GL = gestation length, NRR = nonreturn rate to $56 \mathrm{~d}$, NS $=$ number of services, $\mathrm{SB}=$ stillbirth.
}

under the assumption that there is no correlation between direct and maternal genetic effects. For traits without sire of calf effect, direct genetic covariances are nonexistent, whereas maternal genetic covariances are equivalent to additive genetic parameters.

\section{Methods}

Gibbs sampling was used to generate posterior distributions for all effects in the model. Assumptions included normal distribution for residuals for all traits, and multivariate normal priors for genetic, $\mathrm{SC}, \mathrm{SS}, \mathrm{PE}$, and $\mathrm{T}$ effects. Flat priors were applied for all fixed effects, and priors for covariances were proper (inverted Wishart) with minimal number of degrees of belief. Prior values were estimates obtained with the same models (excluding the effect of AI technician) but different data set extracted in 2003. Conditional distributions were multivariate normal (location parameters) or inverted Wishart (covariance components). Residuals for missing traits were generated using the conditional normal distribution as in Van Tassel and Van Vleck (1996). The total length of the Gibbs chain was 220,000. Burn-in period (20,000 iterations) was determined based on trace plots of selected covariance components. Direct and maternal genetic covariances were calculated for each sample as described in the "Models" section. All estimates were calculated as posterior means of all samples after burn-in. They were: covariance components, ratio of variances (including direct and maternal heritabilities), direct and maternal genetic correlations between traits, correlations between $\mathrm{H}(\mathrm{RYS}), \mathrm{PE}, \mathrm{SS}$, and T effects for respective traits. Posterior standard deviations were estimated as a measure of dispersion of estimated parameters. Independent numbers of samples for covariance components were estimated using the method of initial monotone sequence estimator (Geyer, 1992).

\section{RESULTS}

Effective sample size ranged from 166 to 2976 for $\mathrm{H}$ (RYS) covariances, from 71 to 140 for additive genetic covariances, and from 78 to 118 for PE covariances. Sire of calf, service sire, and AI technician covariances gave slightly higher numbers of independent samples.

Estimates of phenotypic variances and ratios with respect to the total variance for direct genetic, maternal genetic, $\mathrm{H}(\mathrm{RYS}), \mathrm{PE}, \mathrm{SS}, \mathrm{T}$, and $\mathrm{E}$ variances are shown in Table 3. Estimates of the total phenotypic variance (sum of all uncorrelated variance components) corresponded well to the sample phenotypic variances (Table 1). The best fit of the model, measured by proportion of the residual variance in the total variance, was achieved for AFS. Discrete traits (NRR, NS, and SB) showed very poor goodness of fit. Environmental variance due to H(RYS) constituted up to $48 \%$ of the total variance (AFS). Among the remaining traits, CTFS, CE, and CZ had significant environmental variance components $(>10 \%)$. The effect of PE contributed less then $2 \%$ to the total variance for traits measured in consecutive parities. The proportion of variance due to SS and T effects was less than $0.5 \%$.

Maternal heritabilities ranged from 0.02 (SB in cows) to 0.14 (CE in heifers). Direct heritabilities were from 
0.01 (SB in cows) to 0.31 (GL in heifers). Direct heritabilities were in general larger than maternal, except for $\mathrm{CE}$ in heifers and SB in both heifers and cows. Both direct and maternal heritabilities were higher for cow traits than for corresponding heifer traits. Traits measured as intervals in time (AFS, GL, and CTFS in particular) had larger heritabilities than traits of binary or categorical nature. Heritability for NRR was 0.03 for heifers and 0.04 for cows. Smaller values of estimated heritabilities for categorical traits might be a result of using linear models to analyze traits of a categorical nature.

Estimates of maternal genetic and H(RYS) correlations are presented in Table 4. Heifer and cow fertility traits were not the same genetically: genetic correlations between traits observed in both heifers and older cows ranged from 0.31 (SB) to 0.91 (GL). Genetic correlations larger then 0.5 were estimated for remaining traits, namely NRR, FSTC, NS, CE, and CZ. Correlations between different traits (both within and across heifers and cows) in some cases had relatively large posterior standard deviations and therefore they were not always very helpful for deriving definite conclusions concerning relationships between traits. In general, cows bred older for the first time (AFS) had a slightly higher rate of success of the first insemination (NRR), smaller number of services (NS), shorter gestations (GL), and smaller calves (CZ) in both first and later parities. First-parity NRR had a favorable genetic association with NS and FSTC in heifers and older cows, and undesirable correlation with CTFS for later parities. Longer gestations were genetically associated with more stillbirth and bigger calves and had no clear influence on calving difficulty. Heifers that calved with problems had lower fertility in later parities. Random herd environment showed similar trends in terms of correlations between traits. Correlations for the PE effect are shown in Table 5. Large posterior standard deviations were associated with these estimates, indicating their relatively low precision. Results indicated, however, positive associations between common environments in later parities for NS and CE, CTFS and FSTC, as well as CE and SB. Negative relationships could be observed for NRR with GL, and FSTC with GL, which meant that low fertility was associated with longer gestations. Management level of the herd may be partially the reason for these relationships. In herds with a lower management, the fertility will be lower. Additionally, these herds probably have less complete recording of breeding data, which may result in overestimation of gestation length. Both GL and FSTC were based on the same conception date. If this information were inaccurate (missing breeding data, for example) then this would (in most cases) increase GL and decrease FSTC.

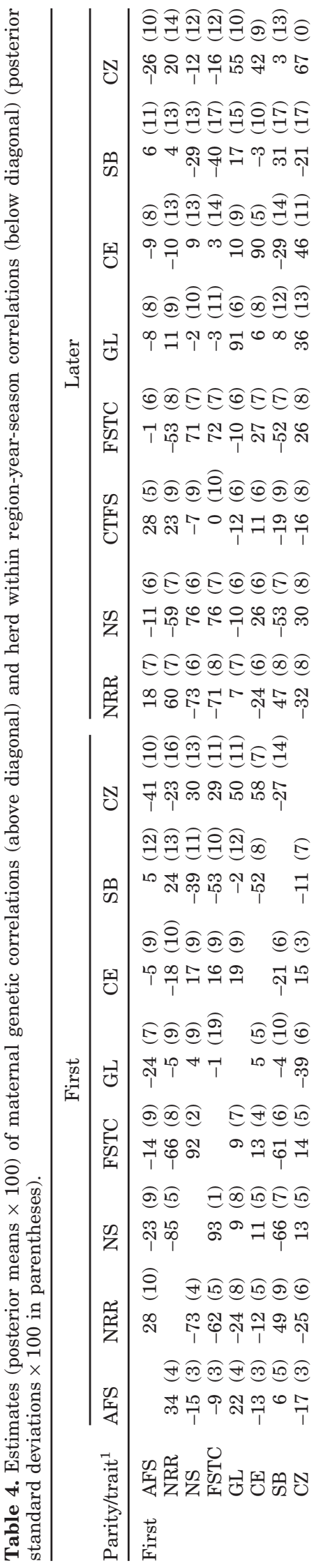

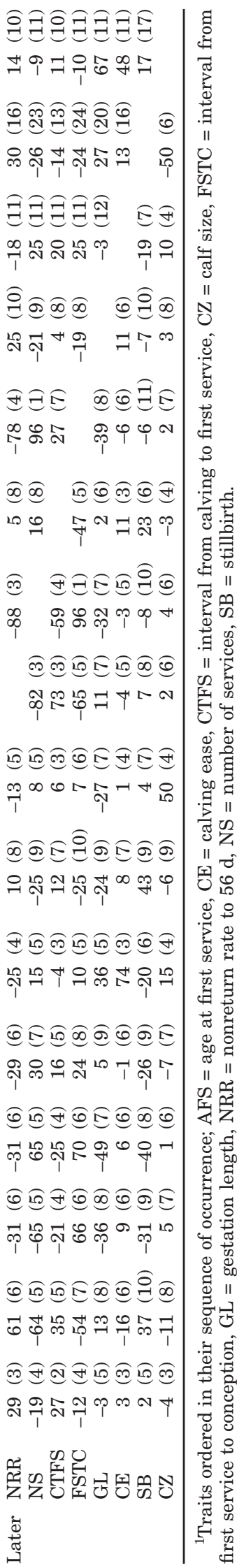


Table 5. Estimates (posterior means $\times 100$ ) of permanent environmental correlations (posterior standard deviations $\times 100$ in parentheses).

\begin{tabular}{|c|c|c|c|c|c|c|c|}
\hline Trait $^{1}$ & NS & CTFS & FSTC & GL & $\mathrm{CE}$ & SB & $\mathrm{CZ}$ \\
\hline NRR & $-48(20)$ & 49 (19) & $70 \quad(12)$ & $-75 \quad(12)$ & $-7 \quad(23)$ & $9(20)$ & $-24 \quad(23)$ \\
\hline NS & & $2(30)$ & $-8 \quad(23)$ & $40(22)$ & 71 (15) & 49 (20) & $12(32)$ \\
\hline CTFS & & & 66 (15) & $-1 \quad(22)$ & $40 \quad(25)$ & $-2(23)$ & $-27(28)$ \\
\hline FSTC & & & & $-64(15)$ & $8(21)$ & $-10(22)$ & $-42(23)$ \\
\hline GL & & & & & 27 (21) & $-6(21)$ & 19 (21) \\
\hline $\mathrm{CE}$ & & & & & & 64 (15) & 27 (24) \\
\hline SB & & & & & & & 43 (23) \\
\hline
\end{tabular}

${ }^{1}$ Traits ordered in their sequence of occurrence; $\mathrm{CE}=$ calving ease, CTFS = interval from calving to first service, $\mathrm{CZ}=$ calf size, FSTC = interval from first service to conception, GL = gestation length, $\mathrm{NRR}=$ nonreturn rate to $56 \mathrm{~d}$, NS = number of services, $\mathrm{SB}=$ stillbirth.

Direct genetic correlations for traits influenced by direct and maternal effects are shown in Table 6. Estimates ranged from -0.40 (SB and $\mathrm{CZ}$ in heifers) to 0.65 (CE and $\mathrm{CZ}$ in heifers). Gestation length had unfavorable correlations with $\mathrm{CE}$ and SB; shorter gestations caused less calving difficulty and fewer stillbirths. Difficult calvings resulted in higher levels of stillbirth, for both heifers and cows. There was no clear relationship between direct and maternal genetic correlations (Table 4) in terms of sign or magnitude. Again, relatively low precision of estimates (high posterior SD) could be observed for some parameters.

Correlation between SS effects for NRR in first vs. later calvings was 0.96 (with posterior SD of 0.07) indicating that a service sire's success rate of insemination should be the same for first and later parities. The respective correlation for the AI technician effect was 0.86 (with posterior SD of 0.11). This meant that quality of the AI service was similar for heifers and older cows. Effects of service sire and AI technician seemed to be important (relative to additive genetic) sources of variation for NRR.

Residual correlations are in Tables 7 and 8 for first and later calvings, respectively. Residuals were uncorrelated between different calvings. The majority of residual cor- relations were close to zero, except those between NRR, NS, and FSTC, which were the traits associated with conception.

\section{DISCUSSION}

Covariance components estimated in this study will be used in the genetic evaluation model for fertility and calving traits of the Canadian Holstein population. The current 4-trait model for AFS (heifers), NRR (heifers and cows), and CTFS (cows) (Van Doormaal et al., 2004) will be expanded to include all 16 traits described in this paper.

Only one sample of the data was used for parameter estimation. Computations were extremely time consuming. Generating 220,000 samples with Gibbs sampling methods required 1.5 mo of computing time. Repeating the analysis on different data subsets was therefore not realistic. Wiggans et al. (2003) showed little influence of the sampled data on covariance components for calving ease. Comparison of the current estimates with parameters obtained on a different subset of the data and a slightly different model (preliminary estimates used as a priori information and starting values for sampling) indicated relatively good agreement between covariance components from a different subset of the data.

Table 6. Estimates (posterior means $\times 100$ ) of direct genetic correlations (posterior standard deviations $\times$ 100 in parentheses).

\begin{tabular}{|c|c|c|c|c|c|c|c|c|}
\hline \multirow{2}{*}{\multicolumn{2}{|c|}{ Parity/trait ${ }^{1}$}} & \multicolumn{3}{|c|}{ First } & \multicolumn{4}{|c|}{ Later } \\
\hline & & $\begin{array}{l}\mathrm{CE} \\
17(10)\end{array}$ & $\begin{array}{ll}\mathrm{SB} & \\
-11 & (14) \\
-39 & (16)\end{array}$ & \multirow{2}{*}{$\begin{aligned} & \mathrm{CZ} \\
& 18(9) \\
& 65(7) \\
&-40(14)\end{aligned}$} & \multirow{2}{*}{$\begin{array}{ll}\text { GL } \\
64 & (6) \\
17 & (11) \\
-9 & (16) \\
20 & (10)\end{array}$} & \multirow{2}{*}{$\begin{aligned} & \mathrm{CE} \\
& 28(11) \\
& 52(11) \\
&-27(18) \\
& 47(11)\end{aligned}$} & \multirow{2}{*}{$\begin{aligned} \mathrm{SB} & \\
-8 & (17) \\
-23 & (19) \\
38 & (19) \\
-21 & (18)\end{aligned}$} & \multirow{2}{*}{\begin{aligned} \multicolumn{1}{c}{ CZ } & \\
28 & $(9) \\
54 & (10) \\
-34 & (15) \\
62 & (8)\end{aligned}$} \\
\hline First & $\begin{array}{l}\text { GL } \\
\text { CE } \\
\text { SB } \\
\text { CZ }\end{array}$ & 17 (10) & $\begin{array}{ll}-11 & (14) \\
-39 & (16)\end{array}$ & & & & & \\
\hline Later & $\begin{array}{l}\text { GL } \\
\text { CE } \\
\text { SB }\end{array}$ & & & & & 33 (11) & $\begin{aligned}-6 & (19) \\
-20 & (20)\end{aligned}$ & $\begin{aligned} 35 & (10) \\
59 & (9) \\
-18 & (19)\end{aligned}$ \\
\hline
\end{tabular}

${ }^{1}$ Traits ordered in their sequence of occurrence; $\mathrm{CE}=$ calving ease, $\mathrm{CZ}=$ calf size, $\mathrm{GL}=$ gestation length, $\mathrm{SB}=$ stillbirth. 
Table 7. Estimates (posterior means $\times 100$ ) of residual correlations for first-parity traits (posterior standard deviations $\times 100$ in parentheses).

\begin{tabular}{|c|c|c|c|c|c|c|c|}
\hline Trait $^{1}$ & NRR & NS & FSTC & GL & $\mathrm{CE}$ & SB & $\mathrm{CZ}$ \\
\hline AFS & $-1(1)$ & 0 (1) & 0 (1) & 7 (1) & 0 (1) & 0 (1) & 0 (1) \\
\hline NRR & & $-59(0)$ & $-49(0)$ & $7(1)$ & 0 (1) & 0 (1) & $2(1)$ \\
\hline NS & & & $90(0)$ & $-2(1)$ & 0 (1) & -1 (1) & $-2(1)$ \\
\hline FSTC & & & & $-1 \quad(1)$ & 0 (1) & 0 (1) & $-2(1)$ \\
\hline GL & & & & & 6 (1) & $8(1)$ & 16 (1) \\
\hline $\mathrm{CE}$ & & & & & & -17 (1) & 24 (1) \\
\hline SB & & & & & & & $-8(1)$ \\
\hline
\end{tabular}

${ }^{1}$ Traits ordered in their sequence of occurrence; $\mathrm{AFS}=$ age at first service, $\mathrm{CE}=$ calving ease, $\mathrm{CZ}=$ calf size, FSTC = interval from first service to conception, GL = gestation length, NRR = nonreturn rate to 56 $\mathrm{d}, \mathrm{NS}=$ number of services, $\mathrm{SB}=$ stillbirth.

Genetic parameters for female reproductive traits have been a subject of numerous publications in recent years (e.g., Jansen, 1986; Jansen et al., 1987; Weller, 1989; Raheja et al., 1989; Hayes et al., 1992; Weigel and Rekaya, 2000; Kadarmideen et al., 2003; Ranberg et al., 2003; Muir et al., 2004). Estimates obtained in the current study were in a good agreement with results from other projects. Heritabilities of most reproductive traits were generally below 0.10 . Interval traits usually had higher estimates of heritability than fertility scores. Genetic correlations between NRR, NS, SB, and CZ in heifer and cows (all estimates not greater than 0.76) confirmed that heifer and cow fertility traits are not necessarily the same traits genetically. On the other hand, for most traits there was at least a moderate genetic correlation between the same trait in heifers and cows, indicating that heifer traits can be used to help evaluate the same trait in cows.

Genetic parameters for calving performance obtained in this study followed, in general, results of others, with Luo et al. (1999) and Muir et al. (2004) providing the latest estimates for Canadian Holsteins. Estimates of genetic parameters between fertility traits and calving performance were less numerous. Muir et al. (2004) showed moderate relationships between $\mathrm{CE}$ and reproductive traits. Kadarmideen et al. (2000) reported that genetic correlations between dystocia and other repro- ductive traits were close to zero. Gestation length and $\mathrm{CZ}$ were included in our study as correlated traits that could influence evaluations of CE and SB. Hansen et al. (2004b) showed that GL had weak genetic associations with SB, CD, and CZ in Danish Holsteins.

Linear animal models were used in this study although some traits were binary (NRR, SB) or categorical (CE, CZ). Theoretically, threshold models were shown to be more correct than linear models for analysis of categorical data (Gianola, 1982). Advantages of threshold over linear models have been shown with simulated data (Meijering and Gianola, 1985). Heritabilities obtained using threshold models were usually higher than those obtained with linear models (Weller et al., 1988; Boichard and Manfredi, 1994; Weigel and Rekaya, 2000). Smaller differences were reported for estimated breeding values from threshold and linear models. Correlations between corresponding threshold and linear model random effect solutions were high (Weller and Ron, 1992; Ramirez-Valverde et al., 2001) indicating little change in ranking of animals between these models. Routine genetic evaluation of categorical fertility and calving traits is mostly based on linear models (Mark, 2004). Applications of threshold methodology have been restricted to sire and sire-maternal grandsire models. Application of threshold animal models to categorical traits was often problematic because of the "extreme category

Table 8. Estimates (posterior means $\times 100$ ) of residual correlations for later parity traits (posterior standard deviations $\times 100$ in parentheses).

\begin{tabular}{|c|c|c|c|c|c|c|c|}
\hline Trait1 & NS & CTFS & FSTC & GL & $\mathrm{CE}$ & SB & $\mathrm{CZ}$ \\
\hline NRR & $-52(0)$ & $4(1)$ & -43 (1) & $6(1)$ & 0 (1) & 0 (1) & $-1 \quad(1)$ \\
\hline NS & & $-5(1)$ & $92(0)$ & -3 (1) & 2 (1) & $-2(1)$ & 2 (1) \\
\hline CTFS & & & $-5(1)$ & 0 (1) & $-1 \quad(1)$ & 0 & $-1 \quad(1)$ \\
\hline FSTC & & & & $-2(1)$ & 1 (1) & -2 (1) & $3(1)$ \\
\hline GL & & & & & $3(1)$ & 11 (1) & $13(1)$ \\
\hline $\mathrm{CE}$ & & & & & & -13 & 13 (1) \\
\hline $\mathrm{SB}$ & & & & & & & 2 (1) \\
\hline
\end{tabular}

\footnotetext{
${ }^{1}$ Traits ordered in their sequence of occurrence; $\mathrm{CE}=$ calving ease, CTFS = interval from calving to first service, $\mathrm{CZ}=$ calf size, FSTC = interval from first service to conception, GL = gestation length, NRR = nonreturn rate to $56 \mathrm{~d}$, NS = number of services, $\mathrm{SB}=$ stillbirth.
} 
problems" where all observations for some subclasses are in the same category (Misztal et al., 1989). Luo et al. (2001) showed also that threshold animal models had problems with convergence, and yielded biased estimates when convergence was reached. Boettcher et al. (1999) found similar problems in threshold animal model for binary longevity data. The threshold model gave biased variances for herd-year and additive genetic effects. Treating effects as random was recommended to lessen the extreme category problems in threshold models (Tempelman, 1998). Threshold models are more demanding computationally than linear models (Misztal et al., 1989). Ramirez-Valverde et al. (2001) showed that switching to multiple-trait from single-trait models increased accuracy more than switching from threshold to linear models. Taking into account all above arguments, no attempt was made at this time to apply threshold models for categorical traits.

The technique of Snell scoring (Snell, 1964) could be used to improve distributional properties of categorical traits. Applying this procedure, however, should not have a major impact on results of this study.

Repeated (in time) reproductive events could have been analyzed by a random regression model. A longitudinal binary animal model has recently been applied to insemination results $(1=$ success, $0=$ failure $)$ of firstparity Holstein cows by Averill et al. (2004). Thaller (1997) suggested the possibility of strong nonadditive genetic effects for fertility traits, but there have been no estimates in the literature for those traits. Weigel (2004) described a failure time (survival analysis) model for female fertility traits to address censoring among cows that were culled or failed to conceive.

Correlations between the additive genetic effect and the sire of calf effect were assumed zero in our model. This was equivalent to the assumption of zero correlation between maternal and direct genetic effects. Reasons were mainly of a computational nature. Estimates of direct with maternal correlations for calving performance traits were shown to be of moderate magnitude (Nadarajah et al., 1989; Luo et al., 1999; Steinbock et al., 2003; Hansen et al., 2004a).

Several studies indicated unfavorable genetic correlation between fertility and production traits in dairy cattle (Kadarmideen et al., 2003; Wall et al., 2003). Correct modeling of fertility traits would require inclusion of production data in the model as a correlated trait, in a similar way as $\mathrm{CZ}$ was included in the current model for analysis of CE and SB. This would further increase the number of traits and create further complications to the model. Estimates of genetic correlation between milk production and NRR in heifers, and milk production and AFS were 0.12 and -0.37 , respectively (Muir et al., 2004), indicating a relatively small impact of production on female fertility in Canadian Holsteins. The effect of milk yield on conception rate was also small for the Holstein cattle in California and Minnesota after accounting for herd-month and DIM effects (Weigel and Rekaya, 2000).

Female fertility is a complex group of traits, and several fertility measures were considered in this project. Other popular fertility measures that were not included in our study are days open and calving interval. They can be easily derived from the correlated traits in our model: days open $=$ CTFS + FSTC; and calving interval $=$ CTFS + FSTC + GL. Genetic correlations between different fertility parameters analyzed in our study indicated that there is not likely a single characteristic that would serve well for selection purposes. Different traits can be combined in a fertility index that could be used in selection for better fertility, defined as the successful birth of a calf following a successful timely conception and gestation period. Reducing the number of traits in the fertility index to 4 or 5 would facilitate better understanding of the index by breeders. Virgin heifer traits are measured relatively early in the cow's life and therefore they should be included in any fertility index. Further research in constructing an optimal fertility index is warranted.

Experimental studies have looked at days to first observed heat, number of heat cycles, progesterone levels in milk, and days from calving to the beginning of luteal activity (van der Lende et al., 2004). The collection of such data in commercial herds is not practical due to the cost and labor that would be needed.

\section{CONCLUSIONS}

Female fertility is a complex set of traits related through genetic and environmental factors. They should be analyzed in a multiple-trait manner, with heifer and cow traits treated as separate but genetically correlated traits. Heritabilities of reproductive characteristics were low. Fertility scores (nonreturn rate, number of services) could be complemented by more highly heritable interval traits (age at first service, calving to first service, first service to conception, gestation length) in terms of a fertility index that would enable efficient selection for better reproductive performance. Traits related to calving performance (dystocia, stillbirth) influence fertility in subsequent parities and therefore they should be considered in a joint model. Calf size and gestation length have considerable genetic components. They should be incorporated in the multiple-trait model for reproductive and calving traits.

\section{ACKNOWLEDGMENTS}

The authors are grateful to the Ontario Ministry of Agriculture, Food and Rural Affairs, DairyGen, and the 
Natural Science and Engineering Research Council for their financial support.

\section{REFERENCES}

Averill, T. A., R. Rekaya, and K. Weigel. 2004. Genetic analysis of male and female fertility using longitudinal binary data. J. Dairy Sci. 87:3947-3952.

Boettcher, P. J., L. K. Jairath, and J. C. M. Dekkers. 1999. Comparison of methods for genetic evaluation of sires for survival of their daughters in the first three lactations. J. Dairy Sci. 79:1117-1125.

Boichard, D., and E. Manfredi. 1994. Genetic analysis of conception rate in French Holstein cows. Acta Agric. Scand. 44:138-145.

Geyer, C. J. 1992. Practical Markov chain Monte Carlo. Stat. Sci. $7: 473-511$

Gianola, D. 1982. Theory and analysis of threshold characters. J. Anim. Sci. 54:1079-1096.

Hansen, M., M. S. Lund, J. Pedersen, and L. G. Christensen. 2004a. Genetic parameters for stillbirth in Danish Holstein cows using a Bayesian threshold model. J. Dairy Sci. 87:706-716.

Hansen, M., M. S. Lund, J. Pedersen, and L. G. Christensen. 2004b. Gestation length in Danish Holsteins has weak genetic associations with stillbirth, calving difficulty, and calf size. Livest. Prod. Sci. 91:23-33.

Hayes, J. F., R. I. Cue, and H. G. Monardes. 1992. Estimates of repeatability of reproductive measures in Canadian Holsteins. J. Dairy Sci. 75:1701-1706.

Jansen, J. 1986. Direct and maternal genetic parameters of fertility traits in Friesian cattle. Livest. Prod. Sci. 15:153-164.

Jansen, J., J. Van Der Werf, and W. De Boer. 1987. Genetic relationships between fertility traits for dairy cows in different parities. Livest. Prod. Sci. 17:337-349.

Kadarmideen, H. N., R. Thompson, M. P. Coffey, and M. A. Kossaibati. 2003. Genetic parameters and evaluations from single- and multiple-trait analysis of dairy cow fertility and milk production. Livest. Prod. Sci. 81:183-195.

Kadarmideen, H. N., R. Thompson, and G. Simm. 2000. Linear and threshold model genetic parameters for disease, fertility and milk production in dairy cattle. Anim. Sci. 71:411-419.

Luo, M. F., P. J. Boettcher, J. C. M. Dekkers, and L. R. Schaeffer. 1999. Bayesian analysis for estimation of genetic parameters of calving ease and stillbirth for Canadian Holsteins. J. Dairy Sci. 82:1848. Available at http://jds.fass.org.

Luo, M. F., P. J. Boettcher, L. R. Schaeffer, and J. C. M. Dekkers. 2001. Bayesian inference for categorical traits with an application to variance components estimation. J. Dairy Sci. 84:694-704.

Mark, T. 2004. Applied genetic evaluations for production and functional traits in dairy cattle. J. Dairy Sci. 87:2641-2652.

Meijering, A., and D. Gianola. 1985. Linear versus nonlinear methods of sire evaluation for categorical traits. Genet. Sel. Evol. 17:115131.

Misztal, I., D. Gianola, and J. L. Foulley. 1989. Computing aspects for a nonlinear method of sire evaluation for categorical traits. J. Dairy Sci. 72:1557-1568.

Muir, B. L., J. Fatehi, and L. R. Schaeffer. 2004. Genetic relationships between persistency and reproductive performance in first-lactation Canadian Holsteins. J. Dairy Sci. 87:3029-3037.

Nadarajah, K., E. B. Burnside, and L. R. Schaeffer. 1989. Factors affecting gestation length in Ontario Holsteins. Can. J. Anim. Sci. 69:1083-1086.
Pryce, J. E., M. D. Royal, P. C. Garnsworthy, and I. L. Mao. 2004. Fertility in high-producing dairy cow. Livest. Prod. Sci. 86:125135.

Raheja, K. L., E. B. Burnside, and L. R. Schaeffer. 1989. Heifer fertility and its relationship with cow fertility and production traits in Holstein dairy cattle. J. Dairy Sci. 72:2665-2678.

Ramirez-Valverde, R., I. Misztal, and J. K. Bertrand. 2001. Comparison of threshold vs linear and animal vs. sire model for predicting direct and maternal genetic effects on calving difficulty in beef cattle. J. Anim. Sci. 79:333-338.

Ranberg, I. M. A., B. Heringstad, G. Klemetsdal, M. Svendsen, and T. Steine. 2003. Heifer fertility in Norwegian dairy cattle: Variance components and genetic change. J. Dairy Sci. 86:2706-2714

Schaeffer, L. R. 1993. Evaluation of bulls for non-return rate within AI organizations. J. Dairy Sci. 76:837-842.

Searle, S. R. 1982. Matrix algebra useful for statistics. John Wiley \& Sons, New York, NY.

Snell, E. J. 1964. A scaling procedure for ordered categorical data. Biometrics 20:592-607.

Steinbock, L., A. Näsholm, B. Berglund, K. Johansson, and J. Philipsson. 2003. Genetic effects on stillbirth and calving difficulty in Swedish Holsteins at first and second calving. J. Dairy Sci. 86:2228-2325.

Tempelman, R. J. 1998. Generalized linear mixed models in dairy cattle breeding. J. Dairy Sci. 81:1428-1444.

Thaller, G. 1997. Genetics and breeding for fertility. Interbull Bull. 18:55-61.

van der Lende, T., L. M. T. E. Kaal, R. M. G. Roelofs, R. F. Veerkamp, C Schrooten, and H. Bovenhuis. 2004. Infrequent milk progesterone measurements in daughters enable bull selection for cow fertility. J. Dairy Sci. 87:3953-3957.

Van Doormaal, B. J., G. Kistemaker, J. Fatehi, F. Miglior, J. Jamrozik, and L. R. Schaeffer. 2004. Genetic evaluation of female fertility in Canadian dairy breeds. Interbull Bull. 32:86-89.

Van Tassel, C. P., and L. D. Van Vleck. 1996. Multiple-trait Gibbs sampler for animal models: flexible programs for Bayesian and likelihood based (co)variance component inference. J. Anim. Sci. 74:2586-2597.

Wall, E., S. Brotherstone, J. A. Wooliams, G. Banos, and M. P. Coffey 2003. Genetic evaluation of fertility using direct and correlated traits. J. Dairy Sci. 86:4093-4102.

Weigel, K. A. 2004. Improving the reproductive efficiency of dairy cattle through genetic selection. J. Dairy Sci. 87(Suppl. E):E86-E92.

Weigel, K. A., and R. Rekaya. 2000. Genetic parameters for reproductive traits of Holstein cattle in California and Minnesota. J. Dairy Sci. 83:1072-1080

Weller, J. I. 1989. Genetic analysis of fertility traits in Israeli dairy cattle. J. Dairy Sci. 72:2644-2650.

Weller, J. I., I. Misztal, and D. Gianola. 1988. Genetic analysis of dystocia and calf mortality in Israeli-Holsteins by threshold and linear models. J. Dairy Sci. 71:2491-2501.

Weller, J. I., and M. Ron. 1992. Genetic analysis of fertility traits in Israeli Holsteins by linear and threshold models. J. Dairy Sci. $75: 2541-2548$.

Westell, R. A., E. B. Burnside, and L. R. Schaeffer. 1992. Evaluation of Canadian Holstein-Friesian sires on disposal reasons of their daughters. J. Dairy Sci. 65:2366-2372.

Wiggans, G. R., I. Misztal, and C. P. Van Tassell. 2003. Calving ease (co)variance components for sire-maternal grandsire threshold model. J. Dairy Sci. 86:1845-1848.

Wilham, R. L. 1963. The covariance between relatives for characters composed of components contributed by related individuals. Biometrics 19:18-27. 